\title{
Theoretical and Practical Aspects of Strategic Management of Balanced Interaction between Subjects of Foreign Economic Activity and State Institutions
}

\author{
Yevhenii Rudnichenko ${ }^{1}$, Halyna Savina ${ }^{2}$, Vasyl Franchuk ${ }^{3}$, Ihor Nestoryshen ${ }^{4}$, \\ Stanislav Savin ${ }^{2}$, Nataliia Havlovska ${ }^{1}$ \\ ${ }^{1}$ Khmelnitsky National University, Khmelnitsky, Ukraine \\ ${ }^{2}$ Kherson National Technical University, Kherson, Ukraine \\ ${ }^{3}$ Lviv State University of Internal Affairs, Lviv, Ukraine \\ ${ }^{4}$ University of State Fiscal Service of Ukraine, Research Institute of Fiscal Policy, Khmelnitsky, Ukraine
}

\begin{abstract}
The main purpose of this article is studying features of strategic management of the interaction of state institutions and enterprises from the position of finding compromise solutions, and the appropriate tools that allow ensuring a balance of interests of society and business in the implementation of foreign economic activity. The methodological basis of the study is game theory, since it is the most acceptable tool used if there is a conflict of interests of the parties. Moreover, the parties to such a conflict often make strategic decisions without knowing about the decisions of their opponents, which we observe in modern business. The game model of interaction between FEA participants and state institutions, developed in the main part of the study, is presented in the form of a non-coalition game. It has been established that the practical implementation of the found combined situation (solution of the game) fully relies on state institutions.
\end{abstract}

Keywords - strategic interaction, foreign economic activity, state institutions, enterprises, game theory, balance of interests, economic development.

DOI: $10.18421 /$ TEM102-27

https://doi.org/10.18421/TEM102-27

Corresponding author: Yevhenii Rudnichenko, Khmelnitsky National University, Khmelnitsky, Ukraine. Email: e.m.rudnichenko@gmail.com

Received: 23 January 2021.

Revised: 30 April 2021.

Accepted: 06 May 2021.

Published: 27 May 2021.

(c) BY-NC-ND (C) 2021 Yevhenii Rudnichenko et al; published by UIKTEN. This work is licensed under the Creative Commons Attribution-NonCommercial-NoDerivs 4.0 License.

The article is published with Open Access at www.temjournal.com

\section{Introduction}

When carrying out foreign economic activity, enterprises are influenced by state institutions interacting with them, as well as transform the economic security system in accordance with the requirements and potential threats that arise in the process of such interaction. In carrying out foreign economic activity, enterprises feel the influence of state institutions, interact with them, as well as transform the system of economic security in accordance with the requirements and potential threats that arise in the process of such interaction. First of all, the changes concern the financial component, as the fiscal functions of regulatory bodies and bodies of protection of economic competition cause the creation of additional financial burden on the enterprises budget. The need for a fiscal burden is determined by the very principles of the functioning of a civilized society; however, it is practically impossible to determine the amount of such a load acceptable to all parties. Therefore, there are certain compromise options (typical for highly developed countries) that allow the state to fulfill its socio-economic functions and not restrain business development. Accordingly, the main purpose of this article is to study the peculiarities of strategic management of the interaction of state institutions and enterprises from the position of finding compromise solutions and appropriate tools that allow balancing the interests of society and business when implementing foreign economic activity.

Analyzing the development trends of modern economic theory in the context of searching for a theoretical basis for studying the influence of state institutions on the activities of business entities, it is necessary to note a slight decrease in the activity of researchers of classical economic theory and the intensification of research on institutional and 
evolutionary lines [10]. When studying the processes of interaction of subjects of influence on the foreign economic activity of an enterprise, it is advisable to use the main provisions of the theory of agency relations, since the coordination of the interests of an enterprise and a state represented by public authorities is characterized by the main substantive processes described within the above theory.

The theory of agency relations has been developed within the framework of the new institutionalism, and its founders are American economists Michael C. Jensen and William H. Meckling. Agency relationships arise when one or more individuals, called principals, hire one or more individuals, called agents, to provide certain services and then give the agents decisionmaking powers [7], [20]. Speaking of agency relations, $\mathrm{W}$. Meckling and M. Jensen prove their applicability to both the private and public sectors: "The problem of influencing the agent so that he maximizes the usefulness of the principal is general. It can be found in any organization based on collective activity: at any level of management in the company, in universities, societies, cooperatives, government agencies and bureaus. "[7]. Therefore, within the framework of agency theory, it is advisable to consider the relationship between economic security entities that interact within the enterprise, and the relationship between business entities and the state, represented by public authorities in general and fiscal authorities in particular.

The main assumptions about the interactive environment of "principal-agent" relationships are [2], [4], [8]: asymmetric information (the first scientific work in this direction was the study [1]; uncertainty - is a measure sufficient to talk about the problem of adaptive, consistent decisions [21]; and assessment complexity.

Therefore, it requires the use of existing tools to assess such interaction. The most acceptable for this purpose is the game theory, as a tool used when a conflict of interests of parties occur. Moreover, the parties of such a conflict make strategic decisions often without knowing the decisions of their opponents.

Game theory did not really exist as a unique field until John von Neumann published the paper On the Theory of Games of Strategy in 1928 [14]. The book "Theory of Games and Economic Behavior" by John von Neumann and Oskar Morgenstern was published later [3]. Also, among the founders of the above-mentioned theory are such as John Nash, Reinhard Selten, and John Harsanyi [5], [11]. John Nash proposed the concept of a situation of equilibrium, which is used in solving non-cooperative games [12], [13]. In 1965, Reinhard Selten introduced his solution concept of subgame perfect equilibrium, which further refined the Nash equilibrium (later he would introduce trembling hand perfection as well) [18], [19].
Game theory in the form known to economists, social scientists, and biologists, was given its first general mathematical formulation by John von Neuman and Oskar Morgenstern [15]. As [6], [9] noted, complex mathematical tools are increasingly used in the studies of economic systems, that allow predicting the scenarios for the development of events, identifying scenarios, and justifying strategic decisions. In the process of implementing foreign economic activity, there is a certain conflict of interests between the state and enterprises, which manifests it in a state's attempt to maximize fiscal revenues, and from the standpoint of enterprises, on the contrary, to minimize mandatory payments. That is why the above-mentioned situation requires balancing interests of parties and finding a certain "balance of interests", which can be implemented using game theory and a corresponding model.

\section{Research Method}

The proposed game model of interaction between the participants of foreign economic activity and state institutions (customs) is presented in the form of a noncoalition $288 \times 20 \times 5$-game, which is denoted as:

$$
\Gamma=\left\langle\left\{G_{\mathbf{D}}, G_{\mathbf{R}}, G_{s}\right\},\left\{\mathbf{M}_{\mathbf{D}}, \mathbf{M}_{\mathbf{R}}, \mathbf{M}_{s}\right\}\right\rangle
$$

$G_{D}, G_{R}, G_{s}$ and $\mathbf{M}_{\mathrm{D}}, \mathbf{M}_{\mathrm{R}}, \mathbf{M}_{\mathrm{s}}-$ sets of pure strategies and three-dimensional matrices of gains of, respectively, state, economic operators and society.

First of all, the establishment / exemption from customs taxation will be described as $d_{1} \in\{0,1\}$. It is clear that $d_{I}=1$ will mean the establishment of customs taxation, $d_{l}=0$ - the exemption from customs duties.

As noted above, the minimum possible value for $d_{2}=0$. The maximum value for $d_{2}$ due to the transition to dimensionless values is 1 . Therefore, $d_{2} \in[0 ; 1]$. However, the restriction here is the following: if $d_{l}=1$, then $d_{2} \epsilon[0 ; 1]$, but if $d_{l}=0$, then always $d_{2}=0$.

It is obvious that $d_{3} \in\{0,1\}$. In the case of a ban on the import / export of goods we get $d_{3}=1$, and in its absence $d_{3}=0$.

The setting of quotas for import / export of goods $\left(d_{4}\right)$ will be expressed in the same dimensionless value within a unit interval $d_{4} \in[0 ; 1]$. As in the case of $d_{1}$ and $d_{2}$, there is a restriction on the value of component $d_{4}$, formed by the ban on the import / export of goods (ie by the value $d_{3}$ ). So, if $d_{3}=1$, then $d_{4}=0$ always, but if $d_{3}=0$, then $d_{4} \in[0 ; 1]$.

Next, the other components are similar to $d_{1}$ and $d_{3}$ : $d_{5} \in\{0,1\}, d_{6} \in\{0,1\}, d_{7} \in\{0,1\}$.

Our current task is to build win matrices (2) for the game model (1):

$\mathbf{M}_{\mathbf{D}}=\left(\delta_{i j k}\right)_{288 \times 20 \times 5}, \quad \mathbf{M}_{\mathbf{R}}=\left(\rho_{i j k}\right)_{288 \times 20 \times 5}, \quad \mathbf{M}_{s}=\left(\sigma_{i j k}\right)_{288 \times 20 \times 5}$ (2), 
where the indices $i, j$ and $k$ mean the situation in the game (1), created by $i$-th, $j$-th and $k$-th pure strategies of a state, economic operators and society, respectively. Values $\delta_{i j k}, \rho_{i j k}$ and $\sigma_{i j k}$ are appropriate gains in this situation.

It is quite clear that this construction can only be carried out through an experts' survey. We already know that it requires giving an estimate in the range from 0 to 1 for 28800 model-game situations. And how can this be done in real conditions? Even if we work with three groups of experts, where each of them will be engaged only in assessing situations for a state, economic operators and society, requiring one expert to provide 28,800 assessments is practically impossible.

The practice of expert assessment shows that the effectiveness and reliability of expert assessments depends on the intensity of the assessment. That is, the more assessments are required from an expert (for a certain, rather short, period of time), the less reliable (or reliable) they will be in the aggregate. In addition, the reliability of expert estimates depends on the accuracy of the estimate - "rough" estimates are more reliable, while the reliability of estimates with "more decimal places" decreases. Therefore, on the one hand, thousands of assessments cannot be required from one expert. On the other hand, grades 0 and 1 or $0,0.25$ and 1 are almost the best grading scale.
What should be the intensity of the assessment in order for the results in the form of matrices (2) to be both reliable and effective (and be obtained in an acceptable period of time)? Obviously, another key factor plays an important role here - the number of experts involved. If we imagine that it is very large, then only a few situations for assessment could be assigned to one expert. Is this possible in practice? It turns out that yes. Nowadays, the dissemination and collection of corporate information via social media is commonplace. Therefore, a survey (questioning) of experts can be performed on the corresponding Facebook page, which can be visited by at least a thousand experts within a few days, leaving their answers.

Each question to an expert is a description of one of the 28,800 situations in the game (1) and the expectation of an answer-score in the simplest case is in the range from 0 to 1 . Each situation consists of 10 items - seven components of state strategy together with two components of economic operators' strategy and one-component strategy of society. Figure 1. Code of software MATLAB-procedure for sequential generation and recording of all 28800 situations of model-game situations in a game (1) shows the program code for sequential generation and recording of all 28,800 situations.

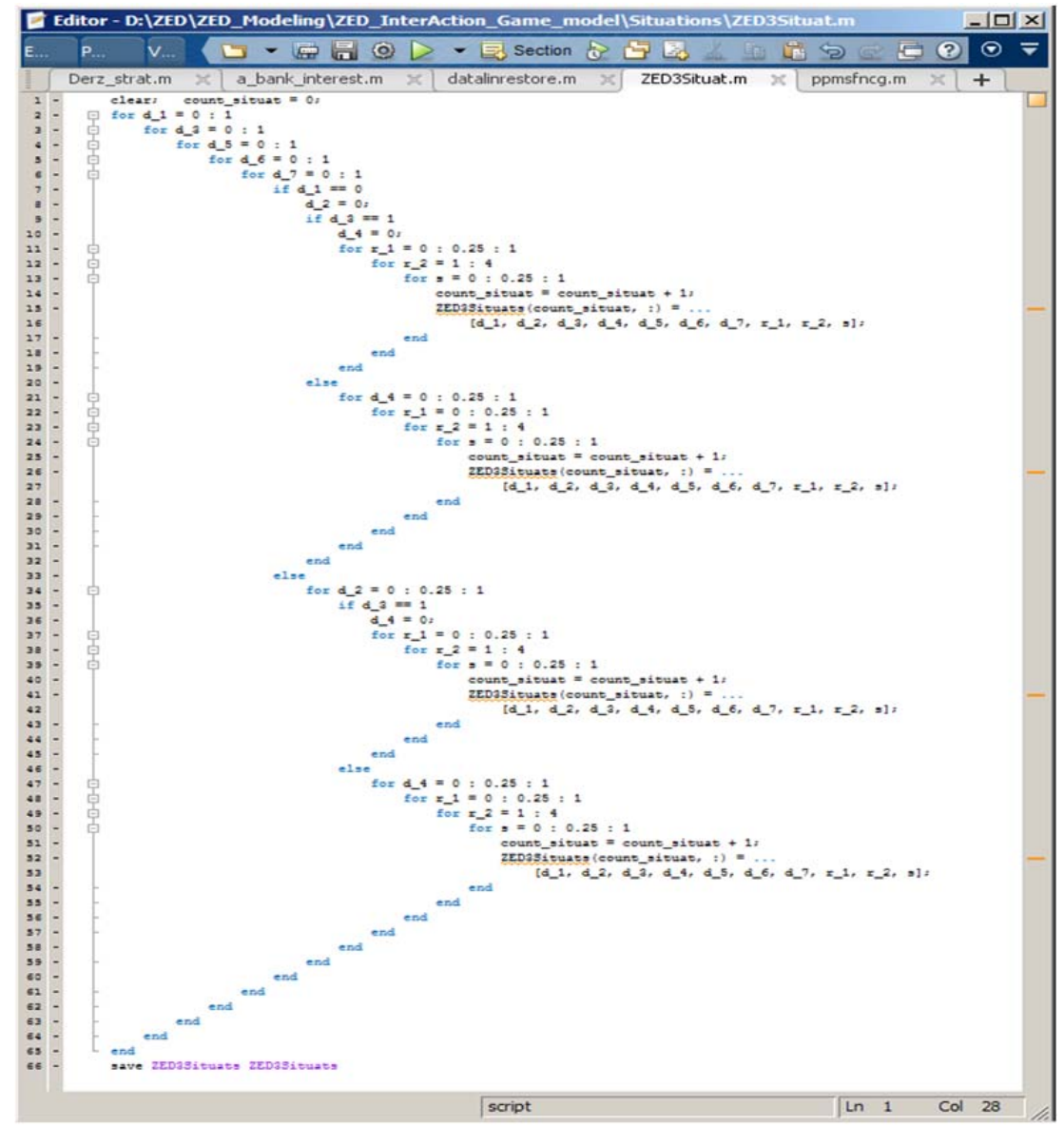

Figure 1. Code of software MATLAB-procedure for sequential generation and recording of all 28800 situations of model-game situations in a game (1) 
The program code of the MATLAB-function for deriving and describing the components of a specific situation by its number is presented in Figure 2. MATLAB function code for deriving and describing the components of a specific situation by its number (from 1 to 28800), where the first input argument of this function is a list of all situations (represented by the value of the components of the strategies that make up these situations) in the game (1).

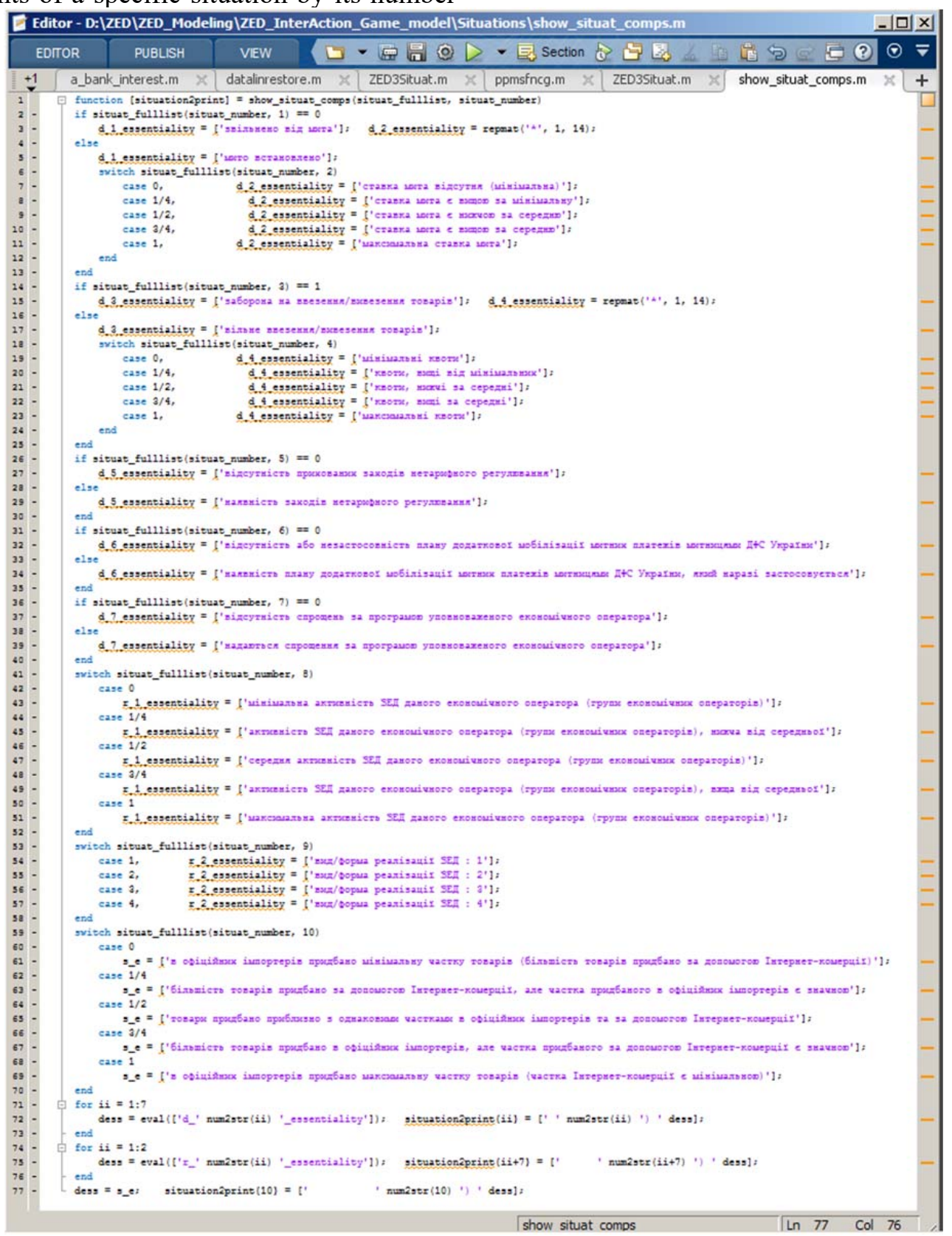

Figure 2. MATLAB function code for deriving and describing the components of a specific situation by its number (from 1 to 28800), where the first input argument of this function is a list of all situations (represented by the value of the components of the strategies that make up these situations) in the game (1)

This conclusion with a description of those 10 points of one of the 28,800 strategies will be in a questionnaire for an expert. Having reviewed these 10 points together, an expert should make an assessment regarding the usefulness for the relevant participant in foreign economic activity in the generated situation.

But, in fact, what answers do we expect from experts? The variant with binary answers ( 0 or 1$)$ proposed in [16] is too trivial for a set of 10 conditional questions. Of course, the option with the option " $50 / 50$ " (or "hard to say") is more acceptable here. In this case, the expert can express his judgment in one of three ratings: $0,0.5,1$. Obviously, the next scale of ratings will be $0,1 / 3,2 / 3,1$. There is no " $50 / 50$ " option in it. This scale is not only more accurate than the previous one - it excludes that "middle" judgment, which plays a negative role, such as "abstained" and practically makes the corresponding assessment of the expert ineffective. 
And here it already becomes clear that the next most accurate scale with the values $0,0.25,0.5,0.75,1$ is redundant.

So, having received a set of 10 questionconditions, the expert must express his judgment on one of four assessments $(0,1 / 3,2 / 3,1)$, where 0 and 1 mean the least and the greatest usefulness, respectively, $1 / 3$ - below average, but not the smallest usefulness, and $2 / 3$ - above average, but not the highest usefulness. However, if the expert cannot make a decision, what cannot be ruled out at all, we will allow the assessment of the consequences of the interaction of interests of FEA participants at customs in the form of one of three intervals: $(0$; $1 / 3),(1 / 3,2 / 3),(2 / 3,1)$. We will immediately convert such interval estimates into points, where we get $1 / 6$, $1 / 2$ and $5 / 6$, respectively.

Since one expert is not able to assess 28800 situations at once (and this is only for one of the FEA participants at customs), we must reduce the number of situations in a survey. An expert needs to familiarize himself with 10 question-conditions, weigh and compare them to give one grade. This will take approximately 1 to 5 minutes. On average, this is 3 minutes, that is, one can hope for 20 estimates for one working time. In one working day, there will be 160 such assessments. Thus, in 90 working days (more than four months) one expert will assess only half assessments (14400 situations) of one payoff matrix. Obviously, this is unacceptable neither from the point of view of a too long evaluation period, nor from the point of view of potential fatigue already in the first weeks from such routine work.

Reasonable assessment duration is one month, during which one expert will provide approximately 3200 assessments for a fixed list of situations. This is $11 \%$ of the total number of situations. Two more expert groups will assess another $22 \%$ of situations. Thus, after agreeing on the judgments of experts, we will be able to assess $33 \%$ of all possible situations. Estimates of other situations will be determined according to the following procedure.

Let, as a result of averaging expert assessments, we have obtained some $2 \times 2$ submatrix of $288 \times 20 \times 5$ matrices, in which three of the four elements are defined. If this submatrix is denoted as:

$$
\left[a_{l q}\right]_{2 \times 2}=\left[\begin{array}{ll}
a_{11} & a_{12} \\
a_{21} & a_{22}
\end{array}\right]
$$

then, on the agreement of experts, the following relationship must be met:

$$
\frac{a_{11}}{a_{12}} \approx \frac{a_{21}}{a_{22}}
$$

Let's mark the missing fourth expert assessment through an asterisk. From here in four cases we will receive:

$$
\begin{gathered}
{\left[\begin{array}{ll}
* & a_{12} \\
a_{21} & a_{22}
\end{array}\right] \rightarrow a_{11}=\frac{a_{12} \cdot a_{21}}{a_{22}},} \\
{\left[\begin{array}{cc}
a_{11} & * \\
a_{21} & a_{22}
\end{array}\right] \rightarrow a_{12}=\frac{a_{11} \cdot a_{22}}{a_{21}},} \\
{\left[\begin{array}{cc}
a_{11} & a_{12} \\
* & a_{22}
\end{array}\right] \rightarrow a_{21}=\frac{a_{11} \cdot a_{22}}{a_{12}},} \\
{\left[\begin{array}{cc}
a_{11} & a_{12} \\
a_{21} & *
\end{array}\right] \rightarrow a_{22}=\frac{a_{12} \cdot a_{21}}{a_{11}},}
\end{gathered}
$$

This procedure will be repeated until only the submatrices of such kind remain:

$$
\begin{aligned}
& {\left[\begin{array}{cc}
* & * \\
a_{21} & a_{22}
\end{array}\right],\left[\begin{array}{cc}
a_{11} & a_{12} \\
* & *
\end{array}\right],\left[\begin{array}{cc}
* & a_{12} \\
a_{21} & *
\end{array}\right]\left[\begin{array}{cc}
a_{11} & * \\
* & a_{22}
\end{array}\right]\left[\begin{array}{cc}
* & a_{12} \\
* & a_{22}
\end{array}\right],} \\
& {\left[\begin{array}{ll}
a_{11} & * \\
a_{21} & *
\end{array}\right],\left[\begin{array}{cc}
* & * \\
* & a_{22}
\end{array}\right],\left[\begin{array}{cc}
* & * \\
a_{21} & *
\end{array}\right],\left[\begin{array}{cc}
a_{11} & * \\
* & *
\end{array}\right],\left[\begin{array}{cc}
* & a_{12} \\
* & *
\end{array}\right],}
\end{aligned}
$$

where formulas (3) - (6) will become inapplicable.

The third of all possible situations for each payoff matrix will be generated randomly. To do this, we will number all situations from 1 to 28800 (Fig. 2). Further, we apply the algorithm built into the MATLAB environment separately for a state, economic operators and society, which revolves a random sequence of $J_{N}$ with $N$ different integers, which are integers from 1 to some maximum integer. In our case, this integer is 28,800 , ie $J_{N} \subset$ $\{\overline{1,28800}\}$. In addition to the specified algorithm, we apply sorting, as a result of which the sequence $J_{9600}$ will become ordered. Actually, the numbers in the sequence $J_{N}$ are linearized by the indices of those elements of the payoff matrix, which value will be estimated. Since we have to generate $33 \%$ of situations to be evaluated, the total number of indexes of situations to be evaluated is: $\mathrm{N}=28800 / 3=9600$ and $J_{9600} \subset\{\overline{1,28800}\}$.

Fig. 3 shows situations generated for expert assessment for each of the matrices (2) marked in dark color. As we can see, the expert assessment will take place on an exclusively random set of situations. In this case, the situations for assessment in each of the matrices $\mathbf{M}_{\mathrm{D}}, \mathbf{M}_{\mathrm{R}}, \mathbf{M}_{\mathrm{s}}$ are selected randomly in their own way. It is clearly seen in Fig. 3, where the black and white "noise" in each of the three rectangles differs from the others.

Having received $33 \%$ of expert estimates, the rest is calculated by formulas (3) - (6). The questionnaire for one group of experts with randomly selected 3200 situations is based on the MATLAB-function for deriving and describing the components of a particular situation by its number (from 1 to 28800), shown in Figure. 3. Situations generated for expert evaluation are shown in matrices (2) in a "flat" form, where each matrix consists of 288 rows and 100 columns. 


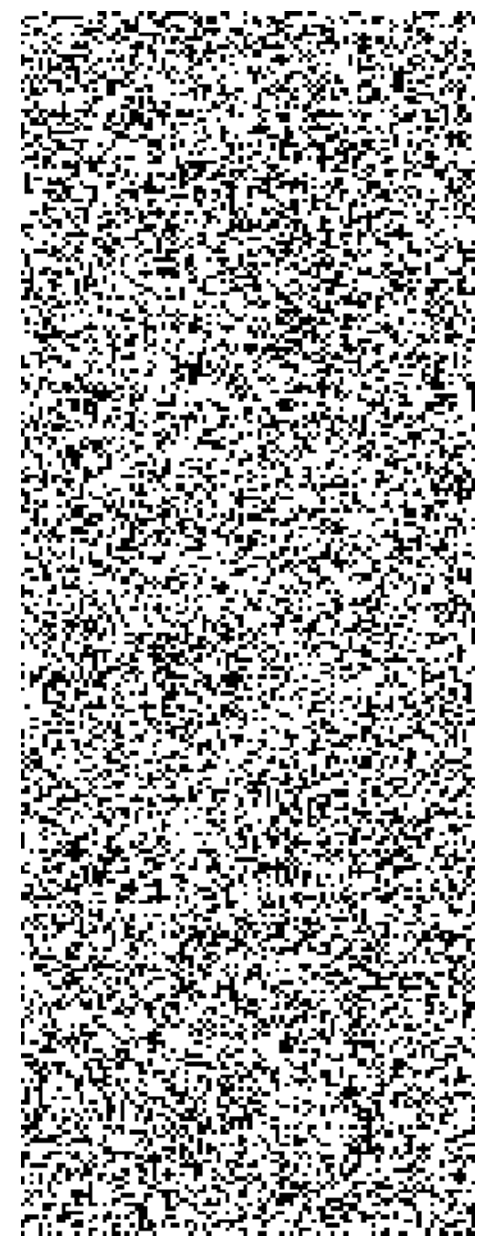

$\mathbf{M}_{\mathbf{D}}$

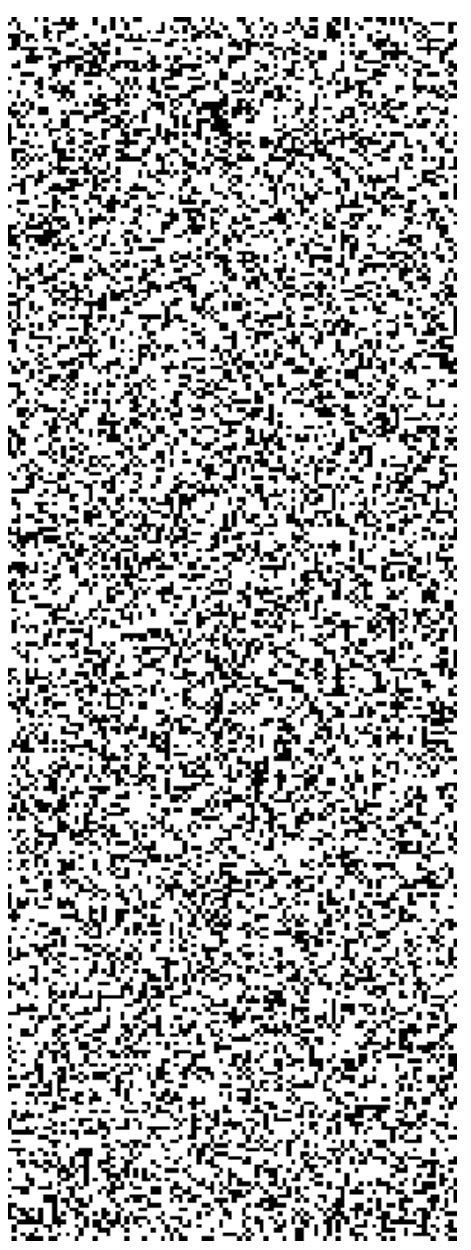

$M_{R}$

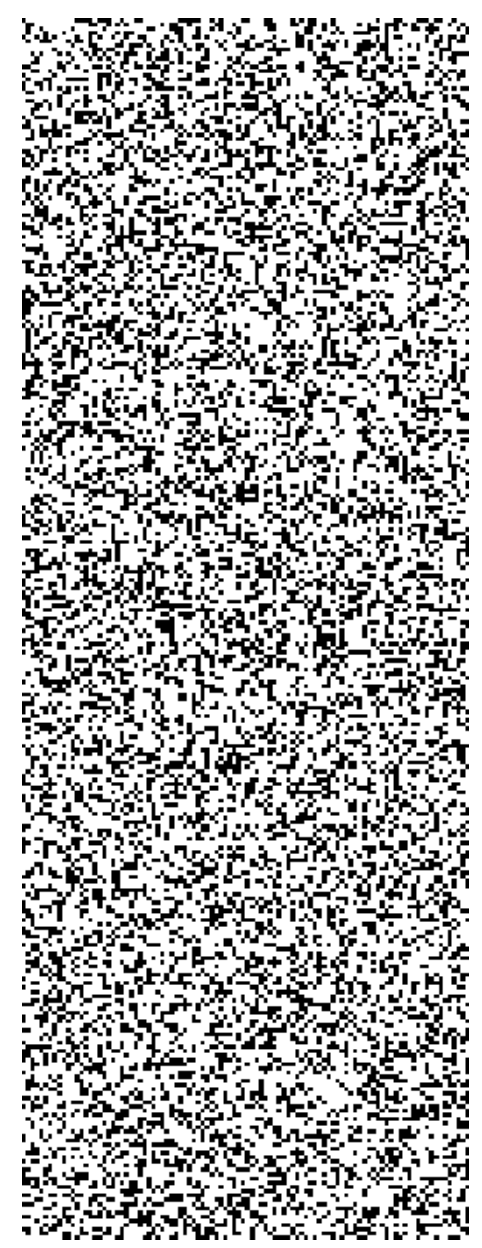

$\mathbf{M}_{\mathrm{s}}$

Figure 3. Situations generated for expert evaluation are shown in matrices (2) in a "flat" form, where each matrix consists of 288 rows and 100 columns

\section{Results}

The best mutual benefit for FEA participants can be achieved on their effective strategies. Such strategies are achieved at the Pareto borders. In the game (1) the situation $\left\{i^{* *}, j^{* *}, k^{* *}\right\}$ is effective (according to Pareto), if there is no situation $\left\{i^{(X)}, j^{(X)}, k^{(X)}\right\}$, which would hold non-strict inequalities [5], [22]:

$$
\begin{aligned}
& \delta_{i^{* *} j^{* *} k^{* *}} \leq \delta_{i}(\mathrm{x}) j^{(\mathrm{x})} k^{(\mathrm{x})}, \\
& \rho_{i^{* *} j^{* *} k^{* *}} \leq \rho_{i^{(\mathrm{x})} j^{(\mathrm{x})} k^{(\mathrm{x})},} \\
& \sigma_{i^{* *} j^{* *} k^{* *}} \leq \sigma_{i^{(\mathrm{x})} j^{(\mathrm{x})} k^{(\mathrm{x})},}
\end{aligned}
$$

and one of the strict inequalities:

$$
\begin{aligned}
& \delta_{i^{* *} j^{* *} k^{* *}}<\delta_{i}(\mathrm{x}) j^{(\mathrm{x})} k^{(\mathrm{x})}, \\
& \rho_{i^{* *} j^{* *} k^{* *}}<\rho_{i}(\mathrm{x}) j^{(\mathrm{x})} k^{(\mathrm{x})}, \\
& \sigma_{i^{* *} j^{* *} k^{* *}}<\sigma_{i^{(\mathrm{x})} j^{(\mathrm{x})} k^{(\mathrm{x})},}
\end{aligned}
$$

The situation in the index numbering $\left\{i^{* *}, j^{* *}, k^{* *}\right\}$ means the situation (in letters):

$$
\left\{d_{1}^{* *}, d_{2}^{* *}, d_{3}^{* *}, d_{4}^{* *}, d_{5}^{* *}, d_{6}^{* *}, d_{7}^{* *}, r_{1}^{* *}, r_{2}^{* *}, s^{* *}\right\}
$$

As it turned out, there are 111 effective situations in this game. In these situations, the conditional usefulness of the participants in foreign economic activity is very different (Table 1), but they all satisfy the efficiency conditions according to (7) and (8). And, it would seem, the best effective situations (9) are those for which the sum of the utilities

$$
\delta_{i^{* *} j^{* *} k^{* *}}+\rho_{i^{* *} j^{* *} k^{* *}}+\sigma_{i^{* *} j^{* *} k^{* *}}
$$

is maximum.

In the table 1, there are two such situations - № 55 and № 56, where the total usefulness (10) is 2,204 and 2,2087 conventional units, respectively. However, in these situations, a state loses too much, especially compared to economic operators. In the other two closest in total efficiency situations №41 and №52 we see almost a similar result. This is not surprising - in situations №52, 55 and 56 a state has a minimum duty rate. However, even after this rate is slightly increased (according to the situation in №41), the conditional usefulness of a state still decreases. It is now clear that these situations are not suitable for the state, although they would provide maximum total usefulness (10). 
Table 1. The list of action options for FEA participants and their results in effective (Pareto) situations in the game

\begin{tabular}{|c|c|c|c|c|c|c|c|c|c|c|c|c|c|}
\hline № & $\mathrm{d}_{1}$ & $\mathrm{~d}_{2}$ & $\mathrm{~d}_{3}$ & $\mathrm{~d}_{4}$ & $\mathrm{~d}_{5}$ & $\mathrm{~d}_{6}$ & $\mathrm{~d}_{7}$ & $\mathrm{r}_{1}$ & $r_{2}$ & $\mathrm{~s}$ & $\delta_{i^{*} j^{*} k^{*}}$ & $\rho_{i^{*} j^{*} k^{*}}$ & $\sigma_{i^{*} j^{*} k^{*}}$ \\
\hline 1. & 0 & 0 & 0 & 0.75 & 0 & 0 & 1 & 1 & 4 & 1 & 0.103963 & 0.851479 & 0.998351 \\
\hline 2. & 0 & 0 & 0 & 1 & 0 & 1 & 1 & 1 & 3 & 1 & 0.11504 & 0.995649 & 0.994517 \\
\hline 3. & 0 & 0 & 0 & 0.75 & 1 & 0 & 1 & 1 & 3 & 1 & 0.088768 & 0.999041 & 0.955199 \\
\hline 4. & 0 & 0 & 0 & 1 & 1 & 1 & 0 & 1 & 1 & 1 & 0.316908 & 0.71429 & 0.975869 \\
\hline 5. & 0 & 0 & 0 & 1 & 1 & 1 & 0 & 1 & 3 & 1 & 0.308064 & 0.768427 & 0.996877 \\
\hline 6. & 0 & 0 & 0 & 1 & 1 & 1 & 1 & 1 & 2 & 1 & 0.321027 & 0.84147 & 0.953016 \\
\hline 7. & 0 & 0 & 0 & 1 & 1 & 1 & 1 & 1 & 3 & 1 & 0.311732 & 0.775653 & 0.972099 \\
\hline 8. & 0 & 0 & 0 & 1 & 1 & 1 & 1 & 1 & 4 & 1 & 0.306384 & 0.838982 & 0.982967 \\
\hline 9. & 0 & 0 & 1 & 0 & 0 & 0 & 0 & 1 & 2 & 1 & 0.169735 & 0.996783 & 0.934002 \\
\hline 10. & 0 & 0 & 1 & 0 & 0 & 0 & 1 & 0.75 & 3 & 0.75 & 0.163443 & 0.980847 & 0.989748 \\
\hline 11. & 0 & 0 & 1 & 0 & 0 & 0 & 1 & 0.75 & 4 & 0.75 & 0.185363 & 0.973619 & 0.975725 \\
\hline 12. & 0 & 0 & 1 & 0 & 1 & 0 & 1 & 0.75 & 2 & 1 & 0.160267 & 0.995808 & 0.962153 \\
\hline 13. & 0 & 0 & 1 & 0 & 1 & 0 & 1 & 0.75 & 4 & 1 & 0.154344 & 0.994319 & 0.996911 \\
\hline 14. & 0 & 0 & 1 & 0 & 1 & 1 & 0 & 0.25 & 1 & 1 & 0.602845 & 0.544265 & 0.229873 \\
\hline 15. & 0 & 0 & 1 & 0 & 1 & 1 & 0 & 0.25 & 2 & 1 & 0.605966 & 0.558828 & 0.117102 \\
\hline 16. & 0 & 0 & 1 & 0 & 1 & 1 & 0 & 0.25 & 3 & 1 & 0.591986 & 0.556854 & 0.174959 \\
\hline 17. & 0 & 0 & 1 & 0 & 1 & 1 & 1 & 0.25 & 1 & 1 & 0.474366 & 0.667436 & 0.365325 \\
\hline 18. & 0 & 0 & 1 & 0 & 1 & 1 & 1 & 0.25 & 2 & 1 & 0.477935 & 0.65618 & 0.580265 \\
\hline 19. & 0 & 0 & 1 & 0 & 1 & 1 & 1 & 0.25 & 3 & 1 & 0.477857 & 0.663903 & 0.469342 \\
\hline 20. & 0 & 0 & 1 & 0 & 1 & 1 & 1 & 1 & 2 & 1 & 0.283186 & 0.880061 & 0.965513 \\
\hline 21. & 1 & 0 & 0 & 0 & 0 & 0 & 0 & 0.75 & 1 & 0.5 & 0.213207 & 0.892805 & 0.973313 \\
\hline 22. & 1 & 0 & 0 & 0.5 & 0 & 0 & 0 & 0 & 4 & 1 & 0.140946 & 0.703576 & 0.999726 \\
\hline 23. & 1 & 0.5 & 0 & 0.5 & 0 & 0 & 0 & 0.75 & 1 & 0.75 & 0.283878 & 0.996968 & 0.007402 \\
\hline 24. & 1 & 0.5 & 0 & 0.5 & 0 & 0 & 0 & 1 & 1 & 0.5 & 0.322808 & 0.995791 & 0.068274 \\
\hline 25. & 1 & 0.5 & 0 & 0.5 & 0 & 0 & 0 & 1 & 3 & 0.5 & 0.340625 & 0.990813 & 0.083469 \\
\hline 26. & 1 & 0.5 & 0 & 0.5 & 0 & 0 & 0 & 1 & 4 & 0.5 & 0.335785 & 0.999415 & 0.001178 \\
\hline 27. & 1 & 0.5 & 0 & 0.75 & 0 & 0 & 0 & 0.75 & 2 & 0.75 & 0.281758 & 0.998967 & 0.009208 \\
\hline 28. & 1 & 0.5 & 0 & 0.75 & 0 & 0 & 0 & 1 & 1 & 0.5 & 0.337125 & 0.993776 & 0.209374 \\
\hline 29. & 1 & 0.5 & 0 & 0.75 & 0 & 0 & 0 & 1 & 2 & 0.5 & 0.326253 & 0.994176 & 0.229872 \\
\hline 30. & 1 & 0.5 & 0 & 0.75 & 0 & 0 & 0 & 1 & 3 & 0.5 & 0.341113 & 0.992798 & 0.004431 \\
\hline 31. & 1 & 0.5 & 0 & 0.25 & 0 & 0 & 1 & 1 & 1 & 1 & 0.240352 & 0.308946 & 0.998787 \\
\hline 32. & 1 & 0.5 & 0 & 0.75 & 0 & 0 & 1 & 1 & 4 & 0.5 & 0.341485 & 0.967409 & 0.008631 \\
\hline 33. & 1 & 0 & 0 & 0.25 & 0 & 1 & 0 & 0.75 & 3 & 0.5 & 0.185611 & 0.942776 & 0.984754 \\
\hline 34. & 1 & 0 & 0 & 0.25 & 0 & 1 & 1 & 0 & 2 & 0.75 & 0.177218 & 0.964843 & 0.992087 \\
\hline 35. & 1 & 0 & 0 & 0.25 & 0 & 1 & 1 & 0.75 & 2 & 1 & 0.173703 & 0.921936 & 0.997972 \\
\hline 36. & 1 & 0 & 0 & 0.25 & 0 & 1 & 1 & 0.75 & 3 & 0.5 & 0.072634 & 0.958274 & 0.998357 \\
\hline 37. & 1 & 0.25 & 0 & 0.25 & 0 & 1 & 1 & 0.75 & 1 & 0.5 & 0.011542 & 0.972272 & 0.997587 \\
\hline 38. & 1 & 0 & 0 & 0 & 1 & 0 & 1 & 0.75 & 4 & 0.75 & 0.213919 & 0.862772 & 0.996822 \\
\hline 39. & 1 & 0 & 0 & 0.25 & 1 & 0 & 1 & 0 & 1 & 0.75 & 0.227888 & 0.960712 & 0.946816 \\
\hline 40. & 1 & 0.25 & 0 & 0.25 & 1 & 0 & 1 & 0.75 & 1 & 0.5 & 0.194869 & 0.9665 & 0.947496 \\
\hline 41. & 1 & 0.25 & $\mathbf{0}$ & 0.25 & 1 & $\mathbf{0}$ & 1 & 0.75 & 3 & 0.5 & 0.22284 & 0.965928 & 0.963326 \\
\hline 42. & 1 & 0.75 & 0 & 0.5 & 1 & 0 & 1 & 1 & 3 & 0.75 & 0.340809 & 0.97013 & 0.009462 \\
\hline 43. & 1 & 0 & 0 & 0 & 1 & 1 & 0 & 0.75 & 1 & 0.75 & 0.27847 & 0.529915 & 0.997738 \\
\hline 44. & 1 & 0 & 0 & 0.25 & 1 & 1 & 0 & 1 & 3 & 0.5 & 0.3419 & 0.66104 & 0.99248 \\
\hline 45. & 1 & 0 & 0 & 0.5 & 1 & 1 & 0 & 1 & 1 & 1 & 0.43563 & 0.778149 & 0.763243 \\
\hline 46. & 1 & 0 & 0 & 0.5 & 1 & 1 & 0 & 1 & 3 & 1 & 0.439641 & 0.780449 & 0.652839 \\
\hline 47. & 1 & 0.5 & 0 & 0.5 & 1 & 1 & 0 & 1 & 3 & 0.75 & 0.642082 & 0.605119 & 0.002736 \\
\hline 48. & 1 & 0.75 & 0 & 0.25 & 1 & 1 & 0 & 1 & 3 & 0.5 & 0.529683 & 0.593857 & 0.223211 \\
\hline 49. & 1 & 1 & 0 & 0 & 1 & 1 & 0 & 1 & 4 & 0.75 & 0.525666 & 0.982746 & 0.007654 \\
\hline 50. & 1 & 0 & 0 & 0 & 1 & 1 & 1 & 0.5 & 4 & 1 & 0.206911 & 0.885659 & 0.986918 \\
\hline 51. & 1 & 0 & 0 & 0 & 1 & 1 & 1 & 1 & 1 & 0.5 & 0.332477 & 0.890637 & 0.804767 \\
\hline 52. & 1 & $\mathbf{0}$ & $\mathbf{0}$ & $\mathbf{0}$ & 1 & 1 & 1 & 1 & 3 & 0.5 & 0.340593 & 0.889793 & 0.943561 \\
\hline 53. & 1 & 0 & 0 & 0 & 1 & 1 & 1 & 1 & 3 & 0.75 & 0.336757 & 0.909804 & 0.503334 \\
\hline 54. & 1 & 0 & 0 & 0.25 & 1 & 1 & 1 & 0.5 & 2 & 1 & 0.20543 & 0.811036 & 0.999331 \\
\hline 55. & 1 & $\mathbf{0}$ & $\mathbf{0}$ & 0.25 & 1 & 1 & 1 & 0.75 & 1 & 0.75 & 0.274527 & 0.999992 & 0.929479 \\
\hline 56. & 1 & $\mathbf{0}$ & $\mathbf{0}$ & 0.25 & 1 & 1 & 1 & 1 & 1 & 0.5 & 0.332022 & 0.935007 & 0.941697 \\
\hline 57. & 1 & 0 & 0 & 0.25 & 1 & 1 & 1 & 1 & 4 & 1 & 0.335212 & 0.972296 & 0.582495 \\
\hline
\end{tabular}


TEM Journal. Volume 10, Issue 2, Pages 707-718, ISSN 2217-8309, DOI: 10.18421/TEM102-27, May 2021.

\begin{tabular}{|c|c|c|c|c|c|c|c|c|c|c|c|c|c|}
\hline № & $d_{1}$ & $d_{2}$ & $\mathrm{~d}_{3}$ & $\mathrm{~d}_{4}$ & $d_{5}$ & $d_{6}$ & $\mathrm{~d}_{7}$ & $\mathrm{r}_{1}$ & $\mathrm{r}_{2}$ & $\mathrm{~s}$ & $\delta_{i^{*} k^{*} k^{*}}$ & $\rho_{i^{*} j^{*} k^{*}}$ & $\sigma_{i^{*} j^{*} k^{*}}$ \\
\hline 58. & 1 & 0 & 0 & 0.5 & 1 & 1 & 1 & 1 & 1 & 1 & 0.432573 & 0.878043 & 0.760716 \\
\hline 59. & 1 & 0 & 0 & 0.5 & 1 & 1 & 1 & 1 & 2 & 1 & 0.43619 & 0.889492 & 0.673856 \\
\hline 60. & 1 & 0 & 0 & 0.5 & 1 & 1 & 1 & 1 & 3 & 0.75 & 0.441697 & 0.748762 & 0.592429 \\
\hline 61. & 1 & 0 & 0 & 0.5 & 1 & 1 & 1 & 1 & 3 & 1 & 0.427423 & 0.878069 & 0.722482 \\
\hline 62. & 1 & 0 & 0 & 0.5 & 1 & 1 & 1 & 1 & 4 & 1 & 0.43992 & 0.878032 & 0.607725 \\
\hline 63. & 1 & 0 & 0 & 0.75 & 1 & 1 & 1 & 1 & 4 & 1 & 0.442025 & 0.875748 & 0.297878 \\
\hline 64. & 1 & 0.5 & 0 & 0.5 & 1 & 1 & 1 & 0.75 & 3 & 0.5 & 0.573577 & 0.714026 & 0.009937 \\
\hline 65. & 1 & 0.5 & 0 & 0.5 & 1 & 1 & 1 & 1 & 1 & 1 & 0.640417 & 0.797649 & 0.00993 \\
\hline 66. & 1 & 0.5 & 0 & 0.5 & 1 & 1 & 1 & 1 & 4 & 0.75 & 0.639494 & 0.951475 & 0.009294 \\
\hline 67. & 1 & 0.5 & 0 & 0.75 & 1 & 1 & 1 & 1 & 2 & 0.75 & 0.626653 & 0.957423 & 0.008531 \\
\hline 68. & 1 & 0.5 & 0 & 1 & 1 & 1 & 1 & 0.75 & 1 & 1 & 0.577424 & 0.962057 & 0.002558 \\
\hline 69. & 1 & 0.5 & 0 & 1 & 1 & 1 & 1 & 1 & 4 & 0.75 & 0.641832 & 0.961834 & 0.007809 \\
\hline 70. & 1 & 0.75 & 0 & 0 & 1 & 1 & 1 & 1 & 1 & 1 & 0.533198 & 0.928301 & 0.087428 \\
\hline 71. & 1 & 0.75 & 0 & 0 & 1 & 1 & 1 & 1 & 4 & 0.75 & 0.535168 & 0.933631 & 0.050943 \\
\hline 72. & 1 & 0.75 & 0 & 0 & 1 & 1 & 1 & 1 & 4 & 1 & 0.540292 & 0.597058 & 0.020757 \\
\hline 73. & 1 & 0.75 & 0 & 0.25 & 1 & 1 & 1 & 1 & 1 & 0.5 & 0.531016 & 0.926449 & 0.135829 \\
\hline 74. & 1 & 0.75 & 0 & 0.25 & 1 & 1 & 1 & 1 & 3 & 0.75 & 0.534728 & 0.631406 & 0.205784 \\
\hline 75. & 1 & 0.75 & 0 & 0.25 & 1 & 1 & 1 & 1 & 4 & 0.5 & 0.527574 & 0.938334 & 0.246234 \\
\hline 76. & 1 & 0.75 & 0 & 0.25 & 1 & 1 & 1 & 1 & 4 & 0.75 & 0.539994 & 0.911493 & 0.200217 \\
\hline 77. & 1 & 1 & 0 & 0.25 & 1 & 1 & 1 & 0.5 & 4 & 0.75 & 0.40194 & 0.973417 & 0.007813 \\
\hline 78. & 1 & 1 & 0 & 0.25 & 1 & 1 & 1 & 1 & 2 & 0.5 & 0.533761 & 0.992252 & 0.006504 \\
\hline 79. & 1 & 1 & 1 & 0 & 0 & 0 & 0 & 0 & 1 & 1 & 0.694001 & 0.024566 & 0.995571 \\
\hline 80. & 1 & 1 & 1 & 0 & 0 & 0 & 0 & 0 & 4 & 0.75 & 0.707114 & 0.072125 & 0.971527 \\
\hline 81. & 1 & 1 & 1 & 0 & 0 & 0 & 0 & 0.25 & 1 & 0.5 & 0.703699 & 0.17203 & 0.926107 \\
\hline 82. & 1 & 1 & 1 & 0 & 0 & 0 & 0 & 0.25 & 3 & 1 & 0.692955 & 0.179833 & 0.967543 \\
\hline 83. & 1 & 1 & 1 & 0 & 0 & 0 & 0 & 0.25 & 4 & 1 & 0.708311 & 0.187565 & 0.913183 \\
\hline 84. & 1 & 1 & 1 & 0 & 0 & 0 & 1 & 0 & 2 & 1 & 0.709799 & 0.001442 & 0.999973 \\
\hline 85. & 1 & 1 & 1 & 0 & 0 & 0 & 1 & 0.25 & 1 & 0.5 & 0.694294 & 0.301517 & 0.733833 \\
\hline 86. & 1 & 1 & 1 & 0 & 0 & 0 & 1 & 0.25 & 1 & 0.75 & 0.695954 & 0.29762 & 0.94851 \\
\hline 87. & 1 & 1 & 1 & 0 & 0 & 0 & 1 & 0.25 & 1 & 1 & 0.696937 & 0.30012 & 0.863738 \\
\hline 88. & 1 & 1 & 1 & 0 & 0 & 0 & 1 & 0.25 & 2 & 0.5 & 0.698251 & 0.299167 & 0.700342 \\
\hline 89. & 1 & 1 & 1 & 0 & 0 & 0 & 1 & 0.25 & 2 & 0.75 & 0.705457 & 0.292 & 0.793059 \\
\hline 90. & 1 & 1 & 1 & 0 & 0 & 0 & 1 & 0.25 & 3 & 0.5 & 0.704809 & 0.294619 & 0.863304 \\
\hline 91. & 1 & 1 & 1 & 0 & 0 & 0 & 1 & 0.25 & 4 & 0.5 & 0.696795 & 0.296132 & 0.919355 \\
\hline 92. & 1 & 1 & 1 & 0 & 0 & 0 & 1 & 0.25 & 4 & 0.75 & 0.705193 & 0.292796 & 0.912664 \\
\hline 93. & 1 & 1 & 1 & 0 & 0 & 0 & 1 & 0.25 & 4 & 1 & 0.704554 & 0.295015 & 0.794832 \\
\hline 94. & 1 & 1 & 1 & 0 & 0 & 1 & 1 & 0.25 & 1 & 0.5 & 0.709662 & 0.180418 & 0.809389 \\
\hline 95. & 1 & 1 & 1 & 0 & 1 & 0 & 0 & 0 & 1 & 1 & 0.709844 & 0.119608 & 0.812119 \\
\hline 96. & 1 & 1 & 1 & 0 & 1 & 0 & 0 & 0 & 2 & 1 & 0.708362 & 0.159021 & 0.829989 \\
\hline 97. & 1 & 1 & 1 & 0 & 1 & 0 & 1 & 0 & 4 & 1 & 0.709439 & 0.078751 & 0.829588 \\
\hline 98. & 1 & 1 & 1 & 0 & 1 & 1 & 0 & 0 & 2 & 1 & 0.991439 & 0.008228 & 0.776969 \\
\hline 99. & 1 & 1 & 1 & 0 & 1 & 1 & 0 & 1 & 1 & 0.5 & 0.641515 & 0.328134 & 0.12954 \\
\hline 100. & 1 & 1 & 1 & 0 & 1 & 1 & 1 & 0 & 2 & 0.75 & 0.996253 & 0.191793 & 0.744549 \\
\hline 101. & 1 & 1 & 1 & 0 & 1 & 1 & 1 & 0 & 3 & 1 & 0.99044 & 0.197493 & 0.77792 \\
\hline 102. & 1 & 1 & 1 & 0 & 1 & 1 & 1 & 0 & 4 & 0.5 & 0.999529 & 0.139296 & 0.607673 \\
\hline 103. & 1 & 1 & 1 & 0 & 1 & 1 & 1 & 0.75 & 1 & 0.5 & 0.637579 & 0.362041 & 0.218879 \\
\hline 104. & 1 & 1 & 1 & 0 & 1 & 1 & 1 & 0.75 & 2 & 0.5 & 0.63596 & 0.353931 & 0.309347 \\
\hline 105. & 1 & 1 & 1 & 0 & 1 & 1 & 1 & 0.75 & 2 & 1 & 0.640879 & 0.352728 & 0.0775 \\
\hline 106. & 1 & 1 & 1 & 0 & 1 & 1 & 1 & 0.75 & 3 & 0.5 & 0.641462 & 0.351753 & 0.407912 \\
\hline 107. & 1 & 1 & 1 & 0 & 1 & 1 & 1 & 1 & 1 & 0.5 & 0.640633 & 0.402226 & 0.204891 \\
\hline 108. & 1 & 1 & 1 & 0 & 1 & 1 & 1 & 1 & 1 & 1 & 0.642108 & 0.40353 & 0.00395 \\
\hline 109. & 1 & 1 & 1 & 0 & 1 & 1 & 1 & 1 & 2 & 0.5 & 0.632179 & 0.408325 & 0.260956 \\
\hline 110. & 1 & 1 & 1 & 0 & 1 & 1 & 1 & 1 & 3 & 0.5 & 0.632054 & 0.418029 & 0.320885 \\
\hline 111. & 1 & 1 & 1 & 0 & 1 & 1 & 1 & 1 & 4 & 0.75 & 0.639912 & 0.406061 & 0.063184 \\
\hline
\end{tabular}


The choice among the effective situations from the list in Table 1 is an independent task. This task does not have an unambiguous interpretation, which depends on the conditions and criteria that guide the person who makes strategic decisions. Even if we consider the optimal situation to be both Nash equilibrium and Pareto efficient, it will not help in this task. For example, the effective situation №69 (with a completely unacceptable utility for society 0.008) is equilibrium at the same time - it is highlighted in bold in Table 1. However, it is unacceptable to society - especially since the strategy $s^{* *}=0.75$ imposed to society here is not entirely feasible in the current environment, when the tendency to buy through the possibilities of Internet commerce is growing. We need to try again to review the list of effective situations this time with a different criterion. To do this, we turn to the method described in [17], which proposes a method of elimination of effective Nash equilibria in trimatric games with asymmetric wins. Such screening, which is applicable to effective situations without Nash equilibrium, is performed by scalarizing to maximize collective usefulness and minimize loss of gain parity, followed by finding distances for equilibrium to three unattainable minima and one unattainable maximum. In more detail, first, the total benefits are standardized by dividing by the sum of all benefits (in our case it is 333 values):

$$
=\frac{u_{i^{* *} j^{* *} k^{* *}}=}{\sum\left\{l^{* *}, h^{* *}, q^{* *}\right\} \in I^{* *}\left(\delta_{l^{* *}} h^{* *} q^{* *}+\rho_{l^{* *} h^{* *} q^{* *}+\sigma_{l^{* *} h^{*} q^{* *}}}\right.},
$$

where $I^{* *}$ is the set of all three indices $\left\{l^{* *}, h^{* *}, q^{* *}\right\}$, corresponding to 111 situations listed in table 1 . Next, the loss of usefulness parity for each pair of FEA participants is determined:

$$
\begin{aligned}
& \lambda_{i^{* *} j^{* *} k^{* *}}^{(\mathrm{D})}=\left|\delta_{i^{* *} j^{* *} k^{* *}}-\rho_{i^{* *} j^{* *} k^{* *}}\right| \\
& \lambda_{i^{* *} j^{* *} k^{* *}}^{(\mathrm{D})}=\left|\delta_{i^{* *} j^{* *} k^{* *}}-\sigma_{i^{* *} j^{* *} k^{* *}}\right| \\
& \lambda_{i^{* *} j^{* *} k^{* *}}^{(\mathrm{S})}=\left|\rho_{i^{* *} j^{* *} k^{* *}}-\sigma_{i^{* *} j^{* *} k^{* *}}\right|
\end{aligned}
$$

where (12), (13), (14) are these losses ("injustices"), respectively, for couples "state economic operators", "state - society", "economic operators - society". Usefulness parity losses (12) (14) are standardized similarly to (11):

$$
\begin{aligned}
& =\frac{\hat{\lambda}_{i^{* *} j^{* *} k^{* *}}^{(\mathrm{D}-\mathrm{EO})}=}{\lambda_{i^{* *} j^{* *} k^{* *}}^{(\mathrm{D})}}, \\
& \hat{\lambda}_{i^{* *} j^{* *} k^{* *}}^{(\mathrm{D}-\mathrm{S})}=
\end{aligned}
$$

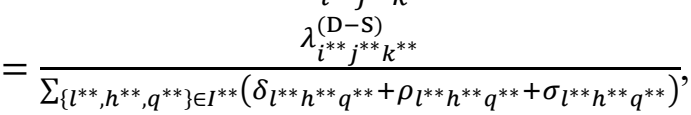

$$
\begin{aligned}
& \hat{\lambda}_{i^{* *} j^{* *} k^{* *}}^{(\mathrm{EO}-\mathrm{S})}= \\
& =\frac{\lambda_{i^{* *} j^{* *} k^{* *}}^{(E O-S)}}{\sum\left\{l^{* *}, h^{* *}, q^{* *}\right\} \in I^{* *}}\left(\delta_{\left.l^{* *} h^{* *} q^{* *}+\rho_{l^{* *}} h^{* *} q^{* *}+\sigma_{l^{* *} h^{* *} q^{* *}}\right)},\right.
\end{aligned}
$$

For the selected weight $\alpha \in(0 ; 1)$ of loss of usefulness parity, 111 distances to the unattainable point of "utopia" are determined (with zero loss of parity and single collective usefulness):

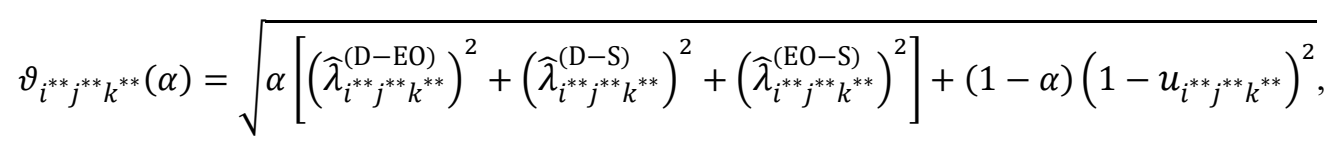

for each three $\left\{i^{* *}, j^{* *}, k^{* *}\right\} \in I^{* *}$. After all, the best situation is the one for which the distance (18) is the smallest, because then the collective usefulness (11) is maximal, and the losses of winning parity (15) (17) are minimal.

Figure 4 (Distribution of distance (18) for 111 effective situations to the unattainable point of "utopia" with $\alpha=0.5$ ) shows the distribution of distance (18) for 111 effective situations in Table 1, and the weight of loss of usefulness parity is taken as the average $(\alpha=0.5)$. As we can see, the minimum of this distance is achieved precisely in situation No. 56, which gives the greatest collective usefulness, but it is not acceptable for a state through a small conditional usefulness. However, this minimum is also preserved for other weights: for $\alpha \in(0.5 ; 0.95)$ the distribution in Fig. 3 practically does not change. Therefore, situation No. 56 is really the best for these three FEA participants at customs, although at first glance it causes distrust from the point of view of a state.
Therefore, according to the situation № 56, the state should set a minimum rate of duty without a ban on the import or export of goods with higher than minimum and lower than average quotas, and simplification should be provided under the program of an authorized economic operator together with the connection of a plan for additional mobilization of customs payments by the customs of Ukraine, and also hidden measures of non-tariff regulation should be applied. In this situation, the activity of the economic operator should be high, and the society should be guided equally by both official importers and Internet commerce. But what will happen when the size of the duty rate is increased together with quotas (without changing strategies of economic operators and society)? It turns out that then the conditional usefulness of a state grows, for example, in situations № 63-69 and № 73-76, where, however, society should be encouraged to purchase most of the goods from official importers. 


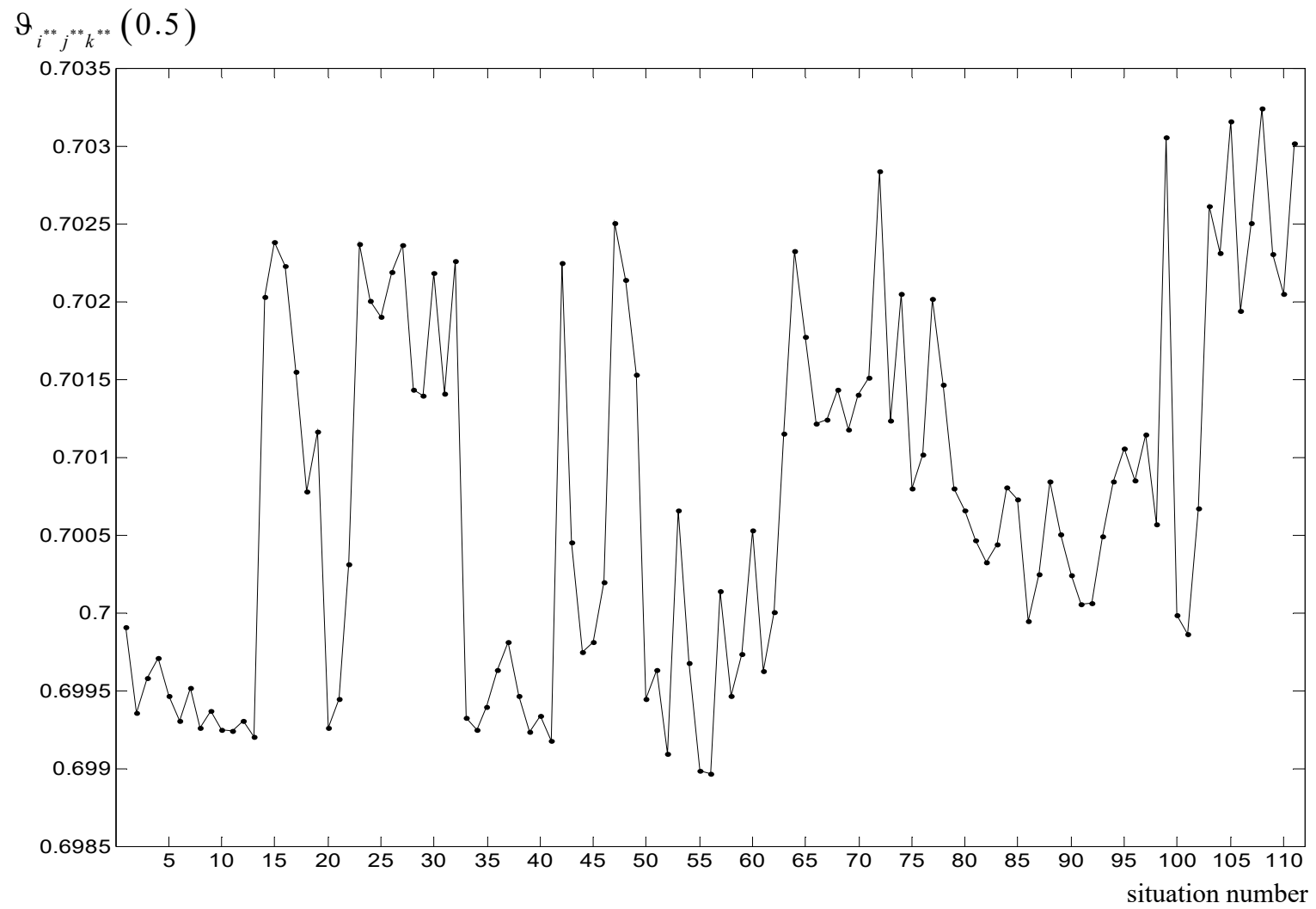

Figure 4. Distribution of distance (18) for 111 effective situations to the unattainable point of "utopia" with $\alpha=0.5$

Therefore, the most effective and almost equilibrium situation for participants in foreign economic activity at customs is a combination of situations № 56, 64-69, 73-76, after which the transition to situation № 63 will be carried out (again with a minimum duty rate, but with increased quotas and incentives to purchase an even larger share of goods from official importers).

With this combination of usefulness ratios, the impact of situations № 63 and № 74 is positive for balancing the interests of the "state-society" pair as opposed to the interests of economic operators. Situations № 63 and № 74 will be included in this combination with some frequencies, while other situations (№ 56, 64 - 69, 73, 75, 76) will have single frequencies. Let the frequency of the situation № 63 be $f_{63}$, and the frequency of the situation № $74-f_{74}$. These frequencies vary from 1 to several hundred. The challenge here is to balance the weighted averages:

$$
\begin{gathered}
\bar{\delta}_{i^{* *} j^{* *} k^{* *}=} \delta_{i^{* *} j^{* *} k^{* *}}(56)+f_{63} \cdot \delta_{i^{* *} j^{* *} k^{* *}}(63)+ \\
+\delta_{i^{* *} j^{* *} k^{* *}}(64)+\delta_{i^{* *} j^{* *} k^{* *}}(65)+\delta_{i^{* *} j^{* *} k^{* *}}(66)+ \\
+\delta_{i^{* *} j^{* *} k^{* *}}(67)+\delta_{i^{* *} j^{* *} k^{* *}}(68)+\delta_{i^{* *} j^{* *} k^{* *}}(69)+ \\
+\delta_{i^{* *} j^{* *} k^{* *}}(73)+f_{74} \cdot \delta_{i^{* *} j^{* *} k^{* *}}(74)+ \\
+\delta_{i^{* *} j^{* *} k^{* *}}(75)+\delta_{i^{* *} j^{* *} k^{* *}}(76), \\
\bar{\rho}_{i^{* *} j^{* *} k^{* *}=} \rho_{i^{* *} j^{* *} k^{* *}}(56)+f_{63} \cdot \rho_{i^{* *} j^{* *} k^{* *}}(63)+ \\
+\rho_{i^{* *} j^{* *} k^{* *}}(64)+\rho_{i^{* *} j^{* *} k^{* *}}(65)+\rho_{i^{* *} j^{* *}} k^{* *}(66)+ \\
+\rho_{i^{* *} j^{* *} k^{* *}}(67)+\rho_{i^{* *} j^{* *} k^{* *}}(68)+\rho_{i^{* *} j^{* *} k^{* *}}(69)+ \\
+\rho_{i^{* *} j^{* *} k^{* *}}(73)+f_{74} \cdot \rho_{i^{* *} j^{* *} k^{* *}}(74)+
\end{gathered}
$$

$$
\begin{gathered}
+\rho_{i^{* *} j^{* *} k^{* *}}(75)+\rho_{i^{* *} j^{* *} k^{* *}}(76), \\
\bar{\sigma}_{i^{* *} j^{* *} k^{* *}=} \sigma_{i^{* *} j^{* *} k^{* *}}(56)+f_{63} \cdot \sigma_{i^{* *} j^{* *} k^{* *}}(63)+ \\
+\sigma_{i^{* *} j^{* *} k^{* *}}(64)+\sigma_{i^{* *} j^{* *} k^{* *}}(65)+\sigma_{i^{* *} j^{* *} k^{* *}}(66)+ \\
+\sigma_{i^{* *} j^{* *} k^{* *}}(67)+\delta_{\sigma j^{* *} k^{* *}}(68)+\sigma_{i^{* *} j^{* *} k^{* *}}(69)+ \\
+\sigma_{i^{* *} j^{* *} k^{* *}}(73)+f_{74} \cdot \sigma_{i^{* *} j^{* *} k^{* *}}(74)+ \\
+\sigma_{i^{* *} j^{* *} k^{* *}}(75)+\sigma_{j^{* *} k^{* *}}(76),
\end{gathered}
$$

So, to minimize the amount of imbalance, i.e. to determine:

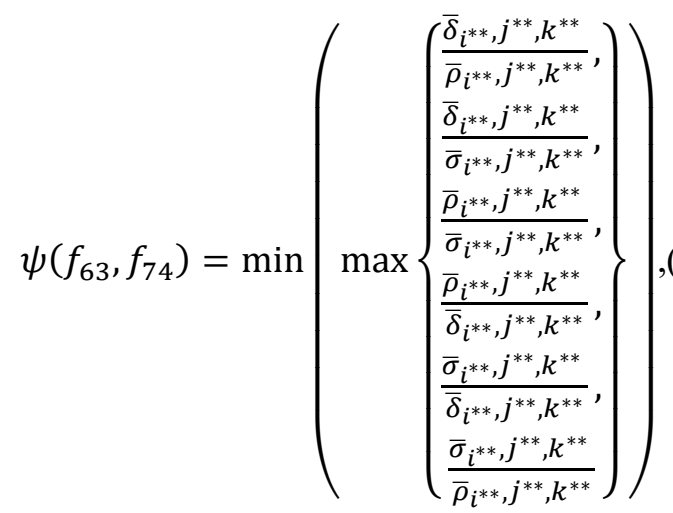

Figure 5 (Imbalance values (22) depending on the frequencies f63 and f74 (local minima are reached in the diagonal depression, but the global minimum is located in the angle closest to the observer)) shows the imbalance (22) depending on the frequencies $f_{63}$ and $f_{74}$. 


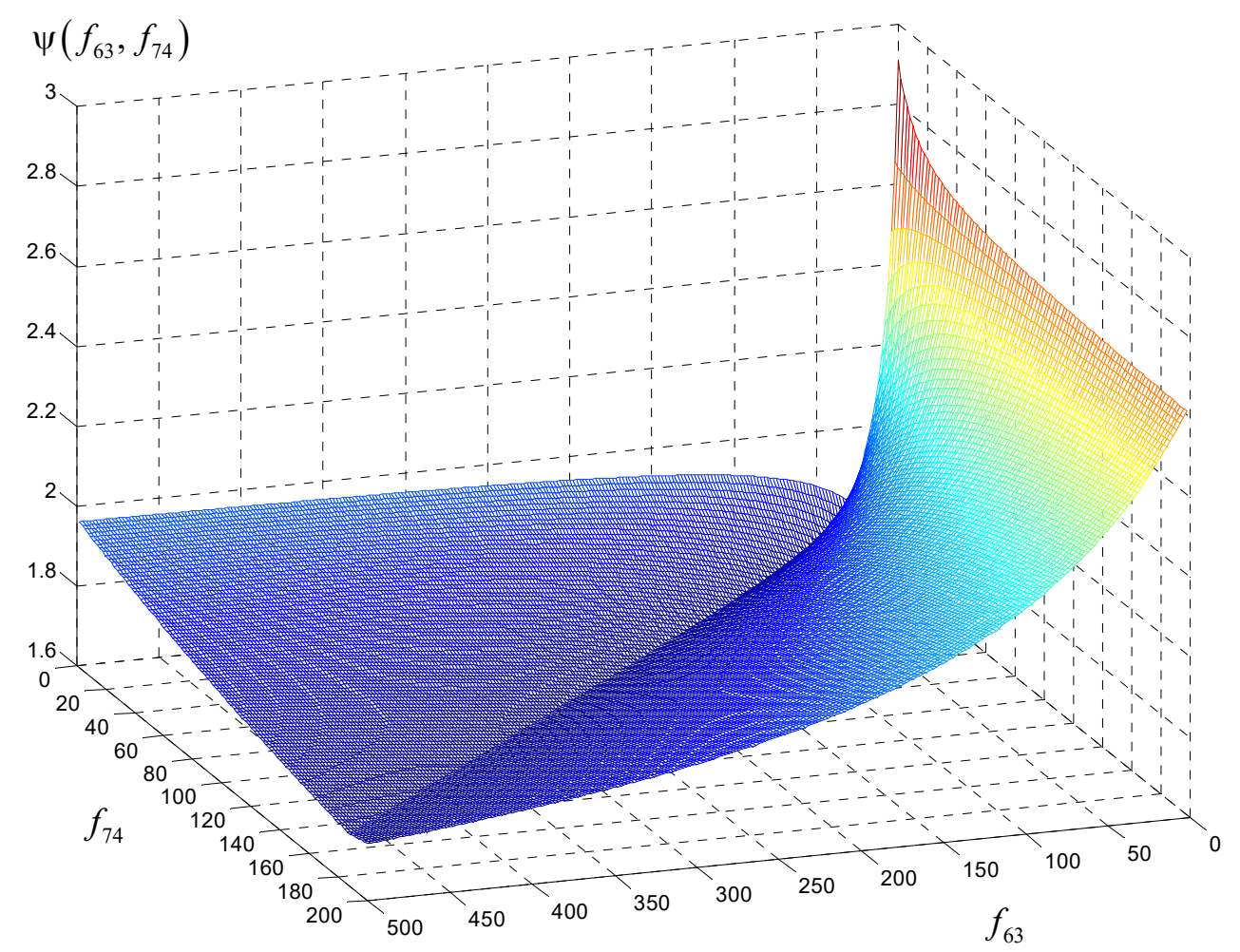

Figure 5. Imbalance values (22) depending on the frequencies $f_{63}$ and $f_{74}$ (local minima are reached in the diagonal depression, but the global minimum is located in the angle closest to the observer)

From this graph it is clear that the optimal values for these frequencies are 498 and 187, respectively. Thus, the optimal combination of situations is the repetition of the cycle of situations № 56, $64-69,73,75,76$ with single frequencies, after which situation № 63 is repeated during 498 rounds, and situation № 74 is repeated during 187 rounds. The round here means a certain period of established rules of foreign economic activity at customs. It can be a day or few days or a week.

If we take a day as one round, then the full implementation of the combination of these situations will take: $1+6+1+1+1+498+187=695$ days, i.e. less than two years.

\section{Conclusions}

In the course of the research it was established that the practical implementation of the found combined situation relies entirely on state institutions. Only they are able to provide appropriate social advertising and incentives for appropriate strategies of economic operators and public demand. The effect of such a combined situation occurs immediately after the end of the 695-round cycle. However, the state must control not only its own strategies during each cycle, because the deviations of economic operators and society from their almost equilibrium strategies are, of course, not only possible but also inert (i.e. the consequences of these deviations are eliminated only over time, not immediately). Therefore, the obtained results are the basic guidelines of mutually beneficial interaction within the triad "state-society-economic operators". Corporate social responsibility and a balanced strategy of state behaviour will benefit society as a whole and ensure the development of the economy through the intensification of foreign economic activity. Therefore, there is a need to find the optimal tools for implementing changes in the interaction of economic agents and a state, which determines the relevance and usefulness of further research.

\section{References}

[1]. Akerlof, G. A. (1970). The Market for" Lemons": Quality Uncertainty and the Market Mechanism. The Quarterly Journal of Economics, 84(3), 488-500.

[2]. Commons, J. R. (1934). Institutional Economics: Its Place in Political Economy.(1961 reprint).

[3]. Kattsoff, L. O. (1945). Theory of Games and Economic Behavior. By John von Neumann and Oskar Morgenstern. Princeton, NJ: Princeton University Press, 1944. 625 pp.

[4]. Dequech, D. (2002). The demarcation between the" old" and the" new" institutional economics: recent complications. Journal of Economic Issues, 36(2), 565-572.

[5]. Harsanyi, J. C., \& Selten, R. (1988). A general theory of equilibrium selection in games. MIT Press Books, 1 .

[6]. Illiashenko, O., Rudnichenko, Y., Momot, T., \& Havlovska, N. (2020). The Enterprise Economic Security System: The State Assessment Using Management Functional Types. International Journal for Quality Research, 14(1). 
[7]. Jensen, M. C., \& Meckling, W. H. (1976). Theory of the firm: Managerial behavior, agency costs and ownership structure. Journal of financial economics, 3(4), 305-360.

[8]. Knight, J., \& Jack, K. (1992). Institutions and social conflict. Cambridge University Press.

[9]. Liubokhynets, L., Rudnichenko, Y., Dzhereliuk, I., Illiashenko, O., Kryvdyk, V., \& Havlovska, N. (2020). Methodological foundations of flexible management and assessing the flexibility of an enterprise economic security system. International Journal of Scientific and Technology Research, 9(3), 4616-4621.

[10]. Lupak, R., Boiko, R., Kunytska-Iliash, M., \& Vasyltsiv, T. (2021). State management of import dependency and state's economic security ensuring: New analysis to evaluating and strategizing. Accounting, 7(4), 855-864.

[11]. Nash, J. F. (1950). Equilibrium points in n-person games. Proceedings of the national academy of sciences, 36(1), 48-49.

[12]. Nash, J. F. (1951). Non-cooperative games. Annals of Mathematics, 54(2), 286-95.

[13]. Nash, J. F., Nagel, R., Ockenfels, A., \& Selten, R. (2012). The agencies method for coalition formation in experimental games. Proceedings of the National Academy of Sciences, 109(50), 20358-20363.

[14]. Neumann, J. V. (1928). Zur theorie der gesellschaftsspiele. Mathematische annalen, 100(1), 295-320.
[15]. Morgenstern, O., \& Von Neumann, J. (1953). Theory of games and economic behavior. Princeton university press.

[16]. Romanuke, V. (2016). Evaluation of Payoff Matrices for Non-Cooperative Games via Processing Binary Expert Estimations. Information Technology and Management Science, 19(1), 10-15.

[17]. Romanuke, V. V. (2018). Maximization of collective utility and minimization of payoff parity losses for ordering and scaling efficient nash equilibria in trimatrix games with asymmetric payoffs. Visnyk Khmel'nyts'koho natsional'noho universytetu. Tekhnichni nauky, (3), 279-281. [in Ukrainian].

[18]. Selten, R. (1983). Evolutionary stability in extensive two-person games. Mathematical Social Sciences, 5(3), 269-363.

[19]. Selten, R. (1988). Evolutionary stability in extensive two-person games-correction and further development. Mathematical Social Sciences, 16(3), 223-266.

[20]. Vasyltsiv, T., Lupak, R., \& Osadchuk, Y. (2017). Assessment of the level of penetration of import dependence in the context of the import substitution policy in Ukraine. Economic annals-XXI, (167), 1317.

[21]. Williamson, O. E. (1985). The economic institutions of capitalism. New York: Free Press.

[22]. Young, H. P., \& Zamir, S. (2015). Handbook of game theory with economic applications (Vol. 4). Elsevier. 